\title{
An improved SWOT approach for conducting strategic planning in the construction industry
}

\author{
Weisheng Lu
}

\begin{abstract}
SWOT analysis (Strength, Weakness, Opportunity, and Threat) has been in use since the 1960s as a tool to assist strategic planning in various types of enterprises including those in the construction industry. Whilst still widely used, the approach has called for improvements to make it more helpful in strategic management. The project described in this paper aimed to study whether the process to convert a SWOT analysis into a strategic plan could be assisted with some simple rationally quantitative model, as an augmented SWOT analysis. By utilizing the mathematical approaches including the quantifying techniques, the "Maximum Subarray" method, and fuzzy mathematics, one or more Heuristic Rules are derived from a SWOT analysis. These Heuristic Rules bring into focus the most influential factors concerning a strategic planning situation, and thus inform strategic analysts where particular consideration should be given. A case study conducted in collaboration with a Chinese international construction company showed that the new SWOT approach is more helpful to strategic planners. The paper provides an augmented SWOT analysis approach for strategists to conduct strategic planning in the construction industry. It also contributes fresh insights into strategic planning by introducing rationally analytic processes to improve the SWOT analysis.
\end{abstract}

Keywords: SWOT, Strategic Planning, Strategy Management, construction companies 


\section{Introduction}

It is generally considered that modern organizations should develop long term strategies in the face of an increasingly dynamic and competitive world. Porter $(1980 ; 1985)$, for example, suggested that a company needs to develop a competitive strategy in order to achieve competitive advantage in a market economy. Miller and Cardinal (1994), by using meta-analytic data drawn from 26 previously published studies, reported that strategic planning does positively affect a firm's performance. In view of the importance of strategies to modern organizations, strategic planning and strategic management have attracted continuing interest from both researchers and executives over past decades.

Various theories and tools have been developed to help top executives formulate and manage their strategies. Whilst the names of pioneers in this area (e.g. Alfred Chandler, Philip Selznick, Igor Ansoff, and Peter Drucker) are still frequently cited, new approaches are constantly emerging, making the discipline one of the liveliest areas of modern management science. Organizations not only provide real-life testbeds for validating theories and tools, but also contribute to the creation of new strategic management approaches (e.g. GE/McKinsey Matrix in the General Electric Company).

Similarly, in the construction sector, strategic planning and strategic management have been advocated. Researchers suggested that construction companies should conduct strategic planning and select long term strategies. A clear strategy is vital if contractors are to survive and thrive in today's construction industry with its increasing dynamics and uncertainties (e.g. Betts et al., 1991; Betts and Ofori, 1992; Betts and Ofori, 1994; Warszawski, 1996; Venegas and Alarcon 1997). Research by others introduced strategic management theories and tested their suitability in the construction industry which is often considered being heterogeneous (e.g. Kale and Arditi, 2002; Kale, 2002; Haan et al., 2002; Flanagan et al, 2007; Lu et al., 2008). Strategic management in construction seemingly often "borrows" theories developed outside the sector.

The terms strategic management and strategic planning both appear frequently in this paper. 
At the risk of simplification, strategic planning is defined as an organization's process of formulating its strategy based on a thorough analysis of its internal and external situations. In comparison with strategic planning, strategic management is the wider process that includes not only strategic planning but also subsequent steps such as strategy implementation and evaluation. Wheelen and Hunger (1995) suggest that typical strategic management consists of four generic processes: environmental scanning (both internal and external), strategy formulation, strategy implementation, and evaluation and control.

Notably, SWOT analysis became one of the most popular tools for strategic planning. SWOT is an acronym for Strengths, Weaknesses, Opportunities and Threats. It has its origins in the 1960s (Learned et al., 1965), and was popularized by Weihrich's (1982) work. It is commonly adopted for the analysis of internal and external situations, in turn encouraging the development of strategies which can cope with these situations. The usage of SWOT analysis has been reported in many fields including that of the construction sector. For example, Shen et al. (2006) use the tool to analyze the situations for foreign-invested construction enterprises in China. Lu et al. (2009) use it in relation to Chinese construction companies in the international construction market.

Despite its widespread use, a large gap nonetheless exists between a SWOT analysis and its following step - strategy formulation. Normally, based on a SWOT analysis, a variety of strategic options will be generated and a best/optimal one will then be selected for implementation. But at its current stage of development, the SWOT analysis is insufficiently informative for the creation of strategic options. It has been reported that a SWOT analysis result is often simply a checklist of internal and external factors, or is simply discarded after the analysis (Hill and Westbrook, 1997). The main purpose of this project, therefore, is to examine one means of filling this gap to see if the strategic planning can be assisted by improving current SWOT approach using rationally analytic quantitative techniques.

However, it is important from the outset to recognize that strategic planning is a mixture of rational analysis and an art form. According to Wheelen and Hunger's strategic management 
model, it appears that deriving strategies from a SWOT analysis is a rational and automatic procedure conceived as a set of logical steps following in sequence. Quantitative approaches and analytical methods are widely employed to determine an appropriate strategic path. It gives a vague impression that strategic planning is a repeatable "scientific" process, whereby a rationally analytical process will lead to appropriate strategies as a guarantee. This actually is not often the case. Research on strategic planning has suggested that strategic decision-making process often incorporates irrationality, intuition, and political behaviour (Elbanna and Child, 2007; Khatri and Ng, 2000). They consider that strategic planning, especially the formulation of strategic options, is not an arena for the application of models or analytical techniques. Instead, it emphasizes strategic planning as an art form involving creativity or other processes that are not currently amenable to scientific analysis.

In fact, strategic planning requires scientific analysis allied to creative thinking. This resonates with two streams of research of this kind on the radar. One tries to increase creativity in the process of formulating strategies. The other, in line with modern thinking, holds that the creative process can be stimulated and improved in the majority of people if done appropriately (Ribeaux and Poppleton, 1978; Cooke and Slack, 1991). Formal brainstorming sessions, for example, are set up to create strategy options, and some research is trying to understand creativity in a scientific way (Dyson, 1990; Boden, 1995). The research reported in this paper is an instance of the stream that is trying to narrow the gap with the help of analytical processes. However, it is not the intention of this research to fully fill the gap with mathematical models and analyses. Instead, the intent is to refine the SWOT analysis information, making it more inspiring for the creation of strategic options. This should be bore in mind by readers before proceeding to the following sections of this paper.

The paper consists of four sections. Firstly, a critical review examines the state of the art of the SWOT approach. Typical shortcomings existing in the SWOT approach are examined. Secondly, an augmented SWOT approach is proposed, so as to distill the essential data needed by strategic planners from the full set of SWOT factors. This approach consists of the application of mathematical methods including matrix calculations, "Maximum Subarray", 
fuzzy set theory. Thirdly, an international construction contractor from China enabled the research team to conduct a case study with the objective of validating the proposed augmented SWOT approach. Next, a discussion follows to explore two issues of concern affecting the SWOT analysis tool.

\section{Implications for practitioners and researchers}

This research provides an augmented SWOT analysis approach for practitioners. It allows strategic planners to identify the most influential SWOT factors, and thus inspires the generation of more promising strategic options. The present research also contributes some fresh insights into strategic planning as a continuingly interesting research field. The research presents researchers with evidence that rationally analytic quantitative techniques can be utilized to improve strategic planning. The paper also encourages researchers to look at how creativity, judgment, and innate skills which cannot be articulated while remain of fundamental importance can improve strategic planning.

\section{A critical review of the SWOT approach}

SWOT is a widely used tool for analyzing internal and external environments in order to attain a systematic understanding of a strategic management situation (Wheelen and Hunger, 1995; Kolter, 1988). In turn, it encourages strategists to adopt a strategy that can best cope with the situation. The philosophy behind the SWOT analysis is that the strategies an organization adopts should match the environmental threats and opportunities with the organization's weaknesses and especially its strengths. It tries to establish a strategic fit between an organization's internal strengths and weaknesses and the opportunities and threats posed by its external environment. This thinking has widely been accepted as a fundamental principle underlying modern strategic management (Beer et al., 2005). Its philosophy can even be traced back to Sun Tzu's The Art of War, "Know your enemy, and know yourself, you can fight a hundred battles with no danger of defeat" (Sun Tzu, BC 600).

Weihrich (1982) proposed a seven-step framework which turns SWOT thinking into some specific steps that an analyst can truly follow. The core of the SWOT analytic framework is 
the TOWS matrix (sometimes called a SWOT matrix), which is shown in Figure 1. To use the framework, users need to identify and evaluate the opportunities and threats facing an organization, and its strengths and weaknesses. The SWOT factors can be fed into the corresponding cells in the TOWS matrix. Users then need to develop strategic options based on the SWOT analysis. There are four generic strategic options, as shown in Figure 1. The $\mathrm{O} / \mathrm{S}$ options maximize strengths and opportunities; the T/S options maximize strengths and minimize the threats; the $\mathrm{O} / \mathrm{W}$ options maximize opportunities and minimize weaknesses; and the T/W options minimize the weaknesses and threats. Weihrich's TOWS matrix provides a systematic fashion to connect internal and external factors in order to stimulate new strategic options. Since then, SWOT analysis has become one of the most popular tools for strategic planning. Nowadays it is taught as one of the basic strategic planning tools in business schools, management colleges, and in other training courses.

\begin{tabular}{|c|c|c|}
\cline { 2 - 3 } \multicolumn{1}{c|}{} & \multicolumn{1}{c|}{ Strengths } & Weaknesses \\
\hline Opportunities & O/S Maxi-Maxi & O/W Maxi-Mini \\
\hline Threats & T/S Mini-Maxi & T/W Mini-Mini \\
\hline
\end{tabular}

Figure 1 The TOWS Matrix

Unlike other tools that became quickly outdated with the fast development of management science, SWOT analysis is still popular. The reasons are many. Firstly, it is inclusive; it fits alongside other theories and tools which emerged later. For example, a SWOT analysis may itself encompass a number of different forms of analysis, e.g. Porter's Five Forces model, Resource-Based Approach, Scenario Analysis, etc (Glaister and Falshaw, 1999). Secondly, it is simple to use. It provides strategy planners with a systematic but simple way for conducting SWOT analyses (Piercy, 1991). In addition, it is flexible. It can be used by different types of organization, including companies, non-profit organizations, government units, and even by individuals.

A number of recently reported studies have tried to enhance the value of the SWOT approach. Some have tried to provide guidelines helping strategic analysts to identify all related 
strengths, weaknesses, opportunities and threats factors. Panagiotou (2003), for example, by noticing that "planners are left without indication as to where to search for such $(\mathrm{S}, \mathrm{W}, \mathrm{O}, \mathrm{T})$ variables", suggested a TELESCOPE OBSERVATIONS framework where each letter stands for an aspect helping the identification of SWOT factors, e.g. T standing for Technological Advancements. The idea is similar to the PEST (Political, Economical, Social, and Technical factors) framework suggested earlier by Weihrich, or the Five Forces Model by Porter (1980) and Resource-Based View by a lot of writers. These developments coincide with the idea that a SWOT analysis should thoroughly analyze internal and external environments. The proliferation of these guidelines implies that analysts worry about missing out any important SWOT factor that subsequent strategies need to take into account.

Other researchers have tried to quantify the SWOT factors. Notably, in a hybrid method called A'WOT (Kurttila et al., 2000), the factors identified by a SWOT analysis are evaluated using the Analytic Hierarchy Process (AHP), a multi-criteria method for determining the relative importance of attributes within a group (Saaty, 1980). The idea of applying the AHP technique within a SWOT framework is to systematically evaluate the SWOT factors and make them commensurable with regard to their relative importance (Kurttila et al., 2000). The concept of quantifying SWOT factors is interesting as it introduces mathematical modeling into SWOT analyses and strategic management processes.

There is a limitation to the traditional SWOT analysis which has not been mentioned by previous researchers. Strategic analysts can often see that the identification of SWOT factors is well guided, and the process well structured. For example, with the assistance of guidance and through certain methods (e.g. brainstorming, group meetings), a SWOT matrix would be derived, which organizes all the SWOT factors in a structured fashion. But when it comes to the following step, the generation of strategic options, most writers are "wise after the event" or arbitrary. These strategic options should be based on current internal and external situations and by analyzing these options a strategist can select an appropriate strategy (Amram and Kulatilaka, 1998; Bowman and Moskowitz, 2001). 
However, only few logical links exist between a SWOT analysis and the generation of strategic options. Currently, there is a gap between these two critical stages. As mentioned above, SWOT analysis experienced a crisis, as Hill and Westbrook (1997) reported that it was often simply used as a checklist of internal and external factors, and sometimes was simply discarded after the analysis. The gap prevents the SWOT analysis from being as helpful as it could be in the generation of strategic options. The only advice given to analysts is "to be creative" in the generation of strategic options that match the SWOT analysis result. Indeed, this process is a highly creative one, and it seems that there is little writers can do with people's creativity (Cooke and Slack, 1991). But the gap referred to above could be narrowed if the traditional SWOT analysis can be improved. If a long list of SWOT factors can be refined into more focused ones, a SWOT analysis could be more effective in the generation of strategic options.

In summary, a critical review shows that the SWOT analysis is a powerful tool for conducting strategic planning. Ensuring a strategic fit between internal and external environments has become a widely accepted principle in strategy management. The SWOT matrix provides a systematic framework connecting internal and external factors hence stimulating new strategies. However, in spite of research into SWOT analysis in recent decades, current SWOT analysis is not informative enough for the formulation of strategic options; a method is needed which pick out and consolidates key influential SWOT factors where strategists must give particular considerations.

\section{Heuristic rules based on an improved SWOT matrix}

From the above, it is clear that the SWOT factors which are most influential for a strategic planning situation should be identified and given more consideration. This section introduces quantitative methods that may help identify these more influential factors.

\section{A quantitative SWOT matrix}

Assuming that after an analysis, all the SWOT factors are agreed and their relative importance determined, a weighted SWOT matrix can be derived as shown in the four cells in 
Figure 2. The SWOT factors could be identified by brainstorming, or by using various guidelines such as the PEST, the TELESCOPE FRAMEWORK, etc. The relative weightings of the SWOT factors could be derived, for instance, by engaging the Likert Scale, or the AHP method. In mathematical language, all the strength factors can be listed in the set

$$
\mathrm{S}=\left\{S_{1}, S_{2}, S_{3}, \ldots, S_{i}\right\}
$$

and their relative importance can be expressed as

$$
\omega_{\mathrm{s}}=\left\{\omega_{s 1}, \omega_{s 2}, \omega_{s 3}, \ldots, \omega_{s i}\right\} \text { where } \sum_{k=s 1}^{s i} \omega_{k}=1 \quad \text {--- Formula (2). }
$$

Similarly, all the weaknesses, opportunities, and threats factors, and their corresponding levels of importance can be expressed in Formula 3 to 8 .

Weaknesses:

$$
\begin{gathered}
\mathrm{W}=\left\{W_{1}, W_{2}, W_{3}, \ldots, W_{j}\right\} \\
\omega_{w}=\left\{\omega_{w 1}, \omega_{w 2}, \omega_{w 3}, \ldots, \omega_{w j}\right\} \text { where } \sum_{k=w 1}^{w j} \omega_{k}=1 \quad \text {--- Formula (4); }
\end{gathered}
$$

Opportunities:

$$
\begin{aligned}
& \mathrm{O}=\left\{O_{1}, O_{2}, O_{3}, \ldots, O_{m}\right\} \\
& \omega_{0}=\left\{\omega_{o 1}, \omega_{o 2}, \omega_{o 3}, \ldots, \omega_{o m}\right\} \text { where } \sum_{k=01}^{o m} \omega_{k}=1
\end{aligned}
$$

Threats:

$$
\begin{aligned}
& \mathrm{T}=\left\{T_{1}, T_{2}, T_{3}, \ldots, T_{n}\right\} \\
& \omega_{\mathrm{T}}=\left\{\omega_{t 1}, \omega_{t 2}, \omega_{t 3}, \ldots, \omega_{t n}\right\} \text { where } \sum_{k=t 1}^{t n} \omega_{k}=1 \quad \text {--- Formula }(8) .
\end{aligned}
$$

It is worth noting that the assignment of weights to these factors could be very subjective by nature. Nonetheless, AHP method (Saaty, 1980) could help reduce the subjectivity by providing a consistency test mechanism to ensure consistency of judgments of strategic planners. 


\begin{tabular}{|c|c|c|c|c|}
\hline 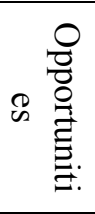 & $\begin{array}{l}\mathrm{O}_{1}, \\
\mathrm{O}_{2}, \\
\mathrm{O}_{3} \\
\ldots \\
\mathrm{O}_{\mathrm{m}}\end{array}$ & $\begin{array}{c}\omega_{\mathrm{o} 1}, \\
\omega_{\mathrm{o} 2}, \\
\omega_{\mathrm{o} 3}, \\
\ldots, \omega_{\mathrm{om}} \\
(\Sigma=1)\end{array}$ & $\begin{array}{c}\mathrm{O} / \mathrm{S} \text { decision options } \\
\text { Maxi-Maxi }\end{array}$ & $\begin{array}{l}\mathrm{O} / \mathrm{W} \text { decision options } \\
\text { Maxi-Mini }\end{array}$ \\
\hline 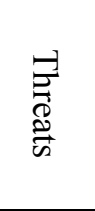 & $\begin{array}{l}\mathrm{T}_{1}, \\
\mathrm{~T}_{2}, \\
\mathrm{~T}_{3}, \\
\ldots \\
\mathrm{T}_{\mathrm{n}}\end{array}$ & $\begin{array}{c}\omega_{\mathrm{t} 1}, \omega_{\mathrm{t} 2}, \\
\omega_{\mathrm{t} 3}, \\
\ldots, \\
\omega_{\mathrm{tn}} \\
(\Sigma=1)\end{array}$ & $\begin{array}{ll}\mathrm{T} / \mathrm{S} \text { decision options } \\
\text { Mini-Maxi }\end{array}$ & $\begin{array}{c}\text { T/W decision options } \\
\text { Mini-Mini }\end{array}$ \\
\hline
\end{tabular}

Figure 2 A Weighted TOWS Matrix

According to the principle of strategic fit, a strategic option should take advantage of strengths, minimize weaknesses, exploit opportunities, and neutralize threats. In reality, not all SWOT factors have a relationship. A company, for example, may not have the strength to take advantage of an emerging opportunity, or to neutralize a threat. Increasing globalization presents a significant opportunity, say, for a UK construction company to venture into booming overseas markets (e.g. China or the Middle East), but long involvement in the indigenous market only may mean the company does not have enough experience (strength) to expand internationally. Weihrich (1982) suggested a mechanism to indicate the relationships between any two SWOT factors. He uses a ' + ' to indicate a match between two factors in different categories, and a ' 0 ' to indicate a weak or non-existent relationship. In this research, the author has introduced a coefficient ' $r$ ' to indicate the relationship between any two SWOT factors, where $\mathrm{r}=1$ for a perfect match, $\mathrm{r}=0$ means a non-existent relationship, and $0<\mathrm{r}<1$ means different levels of relationship range from non-relationship to a perfect match. It is worth noting that the process to determine the relationships may need a lot of interactive, debates, or arguments amongst related strategic planners. It is suggested to use Delphi Method in this process, which may bring out convergence towards a controversial question. This could be facilitated by a facilitator, which is widely used in practice (Dalkey and Helmer, 1963). As a consequence, an interaction SWOT matrix can be developed.

Upon this point, this research has introduced new mechanisms to express different SWOT factors, their corresponding weights, and the relationships between different individual factors. By combining these, a Weighted Interaction SWOT Matrix can be derived. Using the 
Opportunity-Strength $(\mathrm{O} / \mathrm{S})$ matrix as an example, a weighted $\mathrm{O} / \mathrm{S}$ interaction matrix can be derived as shown in Figure 3. A similar method can be used for analyzing the $\mathrm{O} / \mathrm{W}, \mathrm{T} / \mathrm{S}$, and $\mathrm{T} / \mathrm{W}$ matrices.

\begin{tabular}{|c|c|c|c|c|c|c|c|}
\hline & \multicolumn{5}{|c|}{$\begin{array}{l}\text { Strengths } \\
\mathrm{S}_{1}, \stackrel{\mathrm{S}_{2}, \mathrm{~S}_{3}, \ldots, \mathrm{S}_{\mathrm{i}}}{ }\end{array}$} \\
\hline & & & $\omega_{\mathrm{s} 1}$ & $\omega_{\mathrm{s} 2}$ & $\omega_{\mathrm{s} 3}$ & $\ldots$ & $\omega_{\mathrm{si}}(\Sigma=1)$ \\
\hline \multirow{5}{*}{ 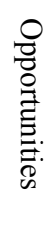 } & \multirow{5}{*}{$\begin{array}{c}\mathrm{O}_{1} \\
\mathrm{O}_{2} \\
\mathrm{O}_{3} \\
\ldots \\
\mathrm{O}_{\mathrm{m}}\end{array}$} & $\omega_{\mathrm{o} 1}$ & $r_{11}$ & $r_{12}$ & $r_{13}$ & $\ldots$ & $\mathrm{r}_{1 \mathrm{i}}$ \\
\hline & & $\omega_{02}$ & $\mathrm{r}_{21}$ & $\mathrm{r}_{22}$ & $r_{23}$ & $\ldots$ & $\mathrm{r}_{2 \mathrm{i}}$ \\
\hline & & $\omega_{03}$ & $\mathrm{r}_{31}$ & $r_{32}$ & $r_{33}$ & $\ldots$ & $\mathrm{r}_{3 \mathrm{i}}$ \\
\hline & & $\ldots$ & $\ldots$ & $\ldots$ & $\ldots$ & $\ldots$ & $\ldots$ \\
\hline & & $\begin{array}{l}\omega_{\mathrm{om}} \\
(\Sigma=1)\end{array}$ & $\mathrm{r}_{\mathrm{m} 1}$ & $\mathrm{r}_{\mathrm{m} 2}$ & $\mathrm{r}_{\mathrm{m} 3}$ & $\ldots$ & $\mathrm{r}_{\mathrm{mi}}$ \\
\hline
\end{tabular}

Figure 3 A Weighted Interaction Matrix $(\mathrm{O} / \mathrm{S})$ between opportunity and strength factors

The weighted interaction $\mathrm{O} / \mathrm{S}$ matrix can be further expressed as Formula (9).

$$
\begin{aligned}
& \text { O/S matrix }=\begin{array}{c}
O_{1} \\
O_{2} \\
O_{3} \\
\ldots \\
O_{m}
\end{array}\left[\begin{array}{cccccc}
\omega_{o 1} r_{11} \omega_{s 1} & \omega_{o 1} r_{12} \omega_{s 2} & \omega_{o 1} r_{m 3} \omega_{s 3} & \ldots & \omega_{o 1} r_{1 i} \omega_{s i} \\
\omega_{o 2} r_{21} \omega_{s 1} & \omega_{o 2} r_{22} \omega_{s 2} & \omega_{o 2} r_{m 3} \omega_{s 3} & \ldots & \omega_{o 2} r_{2 i} \omega_{s i} \\
\omega_{o 3} r_{31} \omega_{s 1} & \omega_{o 3} r_{32} \omega_{s 2} & \omega_{o 3} r_{m 3} \omega_{s 3} & \ldots & \omega_{o 3} r_{3 i} \omega_{s i} \\
\ldots & \ldots & \ldots & \ldots & \ldots \\
\omega_{o m} r_{m 1} \omega_{s 1} & \omega_{o m} r_{m 2} \omega_{s 2} & \omega_{o m} r_{m 3} \omega_{s 3} & \ldots & \omega_{o m} r_{m i} \omega_{s i}
\end{array}\right]_{m \times i} \\
& \left.\begin{array}{c|ccccc}
\multicolumn{1}{c}{} & S_{1} & S_{2} & S_{3} & \ldots & S_{i} \\
O_{1} & R_{11} & R_{12} & R_{13} & \ldots & R_{1 i} \\
O_{2} & R_{21} & R_{22} & R_{23} & \ldots & R_{2 i} \\
O_{3} & R_{31} & R_{32} & R_{33} & \ldots & R_{3 i} \\
\ldots & \ldots & \ldots & \ldots & \ldots & \ldots \\
O_{m} & R_{m 1} & R_{m 2} & R_{m 3} & \ldots & R_{m i}
\end{array}\right]_{m \times i}
\end{aligned}
$$

Formula (9)

In using this analysis, a strategist may initiate strategic options that can make good use of specific strengths and opportunities. This can also be interpreted as meaning that the strategic options will relate some combinations of strength and opportunity factors, as shown in Formula (9). According to the SWOT analysis principle, any strategy adopted should maximize the take up of opportunities and the utilizing of strengths. Hence the task converts to the problem of finding a "Maximum Subarray" from the given weighted interaction $\mathrm{O} / \mathrm{S}$ matrix as illustrated in Formula (9). 


\section{The Maximum Subarray}

The "Maximum Subarray" approach determines an array portion that sums to the maximum value with respect to all possible array portions within the input matrix. Taking matrix A $=\left[\begin{array}{cccc}0 & -2 & -7 & 0 \\ 9 & 2 & -6 & 2 \\ -4 & 1 & -4 & 1 \\ -1 & 8 & 0 & -2\end{array}\right]$ as an example, the Maximum Subarray is $\left[\begin{array}{cc}9 & 2 \\ -4 & 1 \\ -1 & 8\end{array}\right]$ since the sum of all elements in this portion $9+2+(-4)+1+(-1)+8=15$ is the biggest of all possible array portions. The Maximum Subarray was first described by Bentley (1984) in discussing the efficiency of computer programs. It was used to demonstrate how different algorithms can perform with different efficiencies based on the fact that as the dimensions of a matrix become large (e.g. up to a $100 \times 100$ matrix) the calculations required to find the Maximum Subarray can be overwhelming even for modern high-speed computers. Just as for solution of a Rubik's Cube, which is attracting people around the world in the search for quickest permutations, the Maximum Subarray problem is frequently discussed among software programmers and mathematicians aiming to find quicker solutions. In addition, the Maximum Subarray approach has been used in solving such practical problems as sales trends estimation, and the recognition of bitmap images (Takaoka, 2002; Bae and Takaoka, 2005). If all elements of a matrix are non-negative, the problem is trivial, as the entire array represents the solution. If all elements are non-positive, the solution is an empty matrix with value 0 . If computing efficiency is not a significant concern, the problem of finding a Maximum Subarray is solvable, particularly with the assistance of emerging new algorithms and modern computers. More discussion on these algorithms can be found in reports (Bentley, 1984).

The Maximum Subarray approach is introduced in order to identify what the maximal use of opportunities and strengths is. As discussed in above section, any strategy adopted should maximize the take up of opportunities and the utilizing of strengths according to the SWOT analysis principle. The maximal use of opportunities and strengths means all the MOST influential and potential factors which need to be taken account of should be identified first. The meaning of "influential" is that factors should be important, and "potential" means they 
should have relationship so that they can be made use of. Putting it in mathematic language and assuming the $\mathrm{O} / \mathrm{S}$ matrix as shown in Formula (9), the elements of $\mathrm{R}_{\mathrm{mi}}$ express not only the weightings of different factors, but also their relationships. A subarray, as shown in the boxes in Formula (9), contains a certain combination of opportunities and strengths where strategies could be devised to address them. A Maximum subarray indicates the combination of the MOST potential and influential strength and opportunity factors. A strategy should make the maximal use of these strengths and weaknesses.

Although all elements in the matrix are non-negative since $0 \leq R_{m i} \leq 1$, the entire array will not be taken as the Maximum Subarray since we want to exclude any zero element. If $R_{m i}=0$, no relationship exists between an opportunity and a strength. Hereby, we must modify the traditional algorithm in maximum subarray to exclude the zero elements by assuming that $0<$ $\mathrm{Rmi} \leq 1$. The Maximum Subarray for the $\mathrm{O} / \mathrm{S}$ matrix can be expressed as:

$\begin{aligned} \text { MS (O/S)= Maximum Subarray } & {\left[\begin{array}{c}O_{1} \\ O_{2} \\ O_{3} \\ \ldots \\ O_{m}\end{array}\left[\begin{array}{cccccc}R_{11} & R_{12} & R_{13} & \ldots & R_{1 i} \\ R_{21} & R_{22} & R_{23} & \ldots & R_{2 i} \\ R_{31} & R_{32} & R_{33} & \ldots & R_{3 i} \\ \ldots & \ldots & \ldots & \ldots & \ldots \\ R_{m 1} & R_{m 2} & R_{m 3} & \ldots & R_{m i}\end{array}\right]_{m \times i}\right.} \\ & =\begin{array}{c}O_{p} \\ \ldots \ldots \\ O_{q}\end{array}\left[\begin{array}{ccccc}R_{p x} & \ldots \ldots & R_{p y} \\ \ldots \ldots & \ldots \ldots & \ldots \ldots . \\ R_{q x} & \ldots \ldots & R_{q y}\end{array}\right] \text { where } 1 \leq x \leq y \leq i ; 1 \leq p \leq q \leq m ; 0<R \leq 1 ;\end{aligned}$

and when $\operatorname{Sum}\left(R_{p x}+\ldots+R_{p y}+\ldots+R_{q x}+\ldots+R_{1 y}\right)$ is maximum --- Formula (10).

\section{Heuristic rules for generating strategic options}

The set containing all the selected opportunities and strengths factors in the Maximum Subarray is called Heuristic Rule (HR) in this research, as in Formula (11): $H R=\left\{O_{p}, \ldots, O_{q}, S_{x}, \ldots, S_{y}\right\}$ where $O_{p}, \ldots, O_{q}, S_{x}, \ldots, S_{y}$ associate with $\mathrm{MS}(\mathrm{O} / \mathrm{S})$ --- Formula (11).

It informs strategic planners that the strengths and opportunities can be maximally taken advantage of if strategy options cover the elements in the Heuristic Rule. This in turn inspires 
strategic planners to give greater consideration to these factors when creating strategic options. Through the above improvement processes, the result from a traditional SWOT matrix is refined into a Heuristic Rule that identifies the most influential factors. Strategic options should be devised to address these factors associated with a HR.

In real cases, it is also possible that some strategic options would still be effective even though the relevant strength and opportunity factors might not appear in the Maximum Subarray. An array where the sum of all elements in the matrix portion is slightly smaller should not necessarily be neglected, since the strength and opportunity factors concerned can also inspire effective strategic options. However, "slightly" is difficult to define precisely and is a typical concept in fuzzy mathematics. This research makes use of fuzzy set theory to also involve a portion of the $\mathrm{O} / \mathrm{S}$ matrix where the sum of values is not maximal but slightly smaller than that of the Maximum Subarray. The matrix portion (MP) is called slightly sub-maximum subarray and can be expressed in Formula (12):

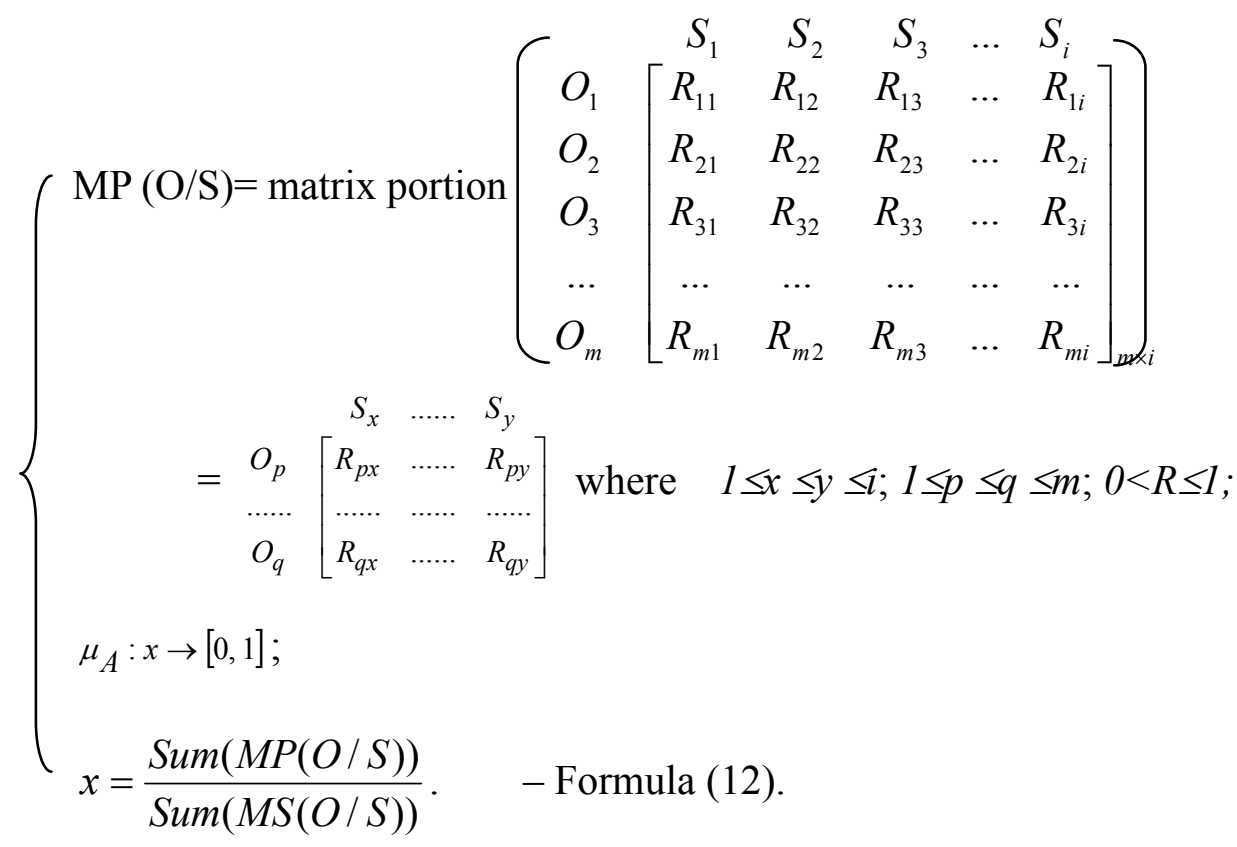

The fuzzy logic was developed by Zadeh (1965) to express some fuzzy phenomena, for example, somebody is tall, or someone is thin. The "slightly" smaller in this model is a typical fuzzy concept so the fuzzy logic is introduced here. In using Formula (12), The sum of $\mathrm{MP}(\mathrm{O} / \mathrm{S})$ is compared with the sum of the maximal subarray $\mathrm{MS}(\mathrm{O} / \mathrm{S})$. A membership 
function $\mu_{A}: x \rightarrow[0,1]$ is developed to indicate whether a subarray is "slightly" smaller than the maximum subarray, and consequently should be considered by chosen strategies. The knowledge in fuzzy math could help understand this "slightly" smaller concept in this model, i.e. El-Naser et al. (2000) gave an example of the membership function. Usually, the development of the membership function is based on subjective judgment and context related. This will be illustrated by a case study later in this paper. For more information, the readers are encouraged to read the relevant contributions about fuzzy language.

The opportunity and strength factors associated with the matrix portions as defined in Formula (12) will constitute various Heuristic Rules as shown in Formula (13):

$H R s=\left\{O_{p}, \ldots, O_{q}, S_{x}, \ldots, S_{y}\right\}$ where $O_{p}, \ldots, O_{q}, S_{x}, \ldots, S_{y}$ associate with $\mathrm{MP}(\mathrm{O} / \mathrm{S})$

--- Formula (13).

Unlike the HR in formula (11), the Heuristic Rules here inform strategic planners that strengths and opportunities would be optimally taken advantage of if decision options can cover the associated factors. The contribution of this newly proposed SWOT analysis is to bring into focus those most influential factors which strategists must give sufficient consideration to when crafting strategies. The same techniques are also applied to the $\mathrm{S} / \mathrm{W}$, $\mathrm{T} / \mathrm{S}$, and $\mathrm{T} / \mathrm{W}$ matrices.

In summary, this section introduces a new method for improving the usefulness of the information derived from a traditional SWOT analysis. The new SWOT approach comprises the following FOUR steps:

(1) Prioritizing SWOT factors by assigning them different weightings using AHP method.

(2) Introducing a co-efficient ' $r$ ' to indicate different levels of relationship between any two factors. By using Delphi method, a weighted interaction SWOT matrix is then derived to indicate the relative importance of different SWOT factors, and their correlations.

(3) Identifying a Maximum Subarray and/or some slightly sub-maximum subarray from the weighted interaction SWOT matrix.

(4) Lastly, Heuristic Rules are derived consisting of only those SWOT factors associated with 
each individual identified subarray. By highlighting the more significant SWOT factors, various Heuristic Rules will help strategists to generate strategic options that can maximally/optimally cope with situations for an organization.

\section{Case study: A Chinese international construction company Background of the case study}

This section describes a case study conducted with a Chinese international construction company. The case study was used to validate the proposed improved SWOT analysis. Unlike the traditional image whereby construction is seen as a local business predominantly using local people, skills, and materials, many of today's firms operate globally outside their home countries. Statistics published by the Engineering News-Record (ENR) (2008), for example, show that the ENR Top 225 International Contractors (TIC 225) logged a total of $\$ 310.25$ billion revenue from construction projects outside their home countries in 2007. Today's construction is becoming an interdependent marketplace with resources being internationally configured because of the globalization of the world economy. The international construction marketplace also provides one of the most sophisticated testbeds for conducting strategic management.

Chinese international construction companies (CICCs) are making impressive progress in the international construction business. The latest statistics from the ENR (2008) show 51 Chinese companies listed amongst the ENR's Top 225 International Contractors (TIC225), gaining in 2007 alone, a total revenue of 22.678 billion U.S. \$ from their overseas market. Lu et al. (2009) reported that CICCs adopt successful strategies to make inroads into the international construction market although the research did not report how they arrive at these strategies. CICCs are able to choose different strategies, e.g. either entering the U.S., European market, or emerging markets such as the Middle East, or staying in their traditional comfort zones of Africa and Asia. The company with which the case study was conducted is one of those who habitually monitor their internal and external environments and formulate international competitive strategies. 
The case study took place in November 2007 in Beijing. Under the term of the data policy agreement, the name of the company is to be kept confidential. It is one of the biggest construction giants in China, having domestic business and international business which is listed in the ENR TIC 225. The years 2007, 2008 and 2009 are critical for the company as the international construction market is slowing down owing to the credit crunch although the full impact had not been fully realized at the time of the study. There was a need for key decision makers to sit down, look at the external and internal environments, and devise appropriate strategies in order to get through this difficult period. The proposed SWOT approach was introduced in a workshop, which formed part of the whole strategic decision process.

\section{Methodology of the case study}

The attendees at the workshop were key decision makers including the chairman, general manager, deputy general managers, Chief-Finance-Officer, and General Engineer. All were familiar with the tradition SWOT analysis approach. Attendees were first invited to compile a strengths, weaknesses, opportunities, and threats list. As a result, four relatively long lists were produced. This process ran smoothly. Participants have been encouraged to provide all potential S,W,O,T factors which were to be simply and honestly written down. Figure 4 lists the 'strengths' and 'opportunities' as examples. The authors have consolidated some factors where the meanings were identical.

\begin{tabular}{|l|l|}
\cline { 2 - 2 } \multicolumn{1}{c|}{} & Internal Strengths \\
\cline { 2 - 2 } & S1: Low cost/good value for money \\
& S2: Abundant cheap manpower \\
& S3: Strong design and construction capacity \\
& S4: Profits from multiple portfolios \\
\hline External Opportunities: & S5: Hard working \\
O1: More open global construction market & S6: Reputation \\
\hline & S7: Plenty and cheap construction materials available \\
& S8: Experience in Asia and Africa markets \\
\hline & S9: Strong support from the government \\
\hline & S10: Particularly specialized in housing/office buildings \\
\hline
\end{tabular}


$\mathrm{O} 2$ : Domestic construction market is still going strong

O3: Olympic projects

O4: Will be listed in the stock market

O5: Increasing collaboration and partnering amongst

international competitors

O6: Globalization provides a chance for leap-forward

development

Figure 4 Internal strengths and external opportunities faced by the Chinese construction company

As the second step, the attendees were asked to prioritize all the S,W,O,T factors. There were more controversies over the weights of these SWOT factors. A combined approach of AHP and Delphi method was adopted to derive the weights of these SWOT factors. This is similar to any group decision process and issues of politics and bureaucracy were evident. The Delphi method was introduced as it envisaged the interaction between these key decision makers. The method helped derive a summary of the weights. Later, the weights should pass a consistency test required by AHP method otherwise further requests were made to rate the relative importance again. The author worked as a facilitator in this process with the assistance of a little program called AHP Calculator purposely developed by the author. A consensus over the relative weights was reached eventually as tabulated in Figure 5.

Internal Strengths

S1: Low cost/good value for money

S2: Abundant cheap manpower

S3: Strong design and construction capacity

S4: Profits from multiple portfolios

S5: Hard working

S6: Reputation

S7: Plenty and cheap construction materials available

S8: Experience in Asia and Africa markets

S9: Strong support from the government

S10: Particularly specialized in housing/office buildings

\begin{tabular}{|l|l|l|l|l|l|l|l|l|l|}
\hline$\omega_{\mathrm{S} 1}$ & $\omega_{\mathrm{S} 2}$ & $\omega_{\mathrm{S} 3}$ & $\omega_{\mathrm{S} 4}$ & $\omega_{\mathrm{S} 5}$ & $\omega_{\mathrm{S} 6}$ & $\omega_{\mathrm{S} 7}$ & $\omega_{\mathrm{S} 8}$ & $\omega_{\mathrm{S} 9}$ & $\omega_{\mathrm{S} 10}$ \\
\hline 0.15 & 0.09 & 0.10 & 0.09 & 0.06 & 0.12 & 0.08 & 0.13 & 0.09 & 0.09 \\
\hline
\end{tabular}


O1: More open global construction market

O2: Domestic construction market is still going strong

O3: Olympic projects

O4: Will be listed in the stock market

O5: Increasing collaboration and partnering amongst international competitors

O6: Globalization provides a chance for leap-forward development

\begin{tabular}{|l|l|}
\hline$\omega_{\mathrm{O} 1}$ & 0.13 \\
\hline$\omega_{\mathrm{O} 2}$ & 0.18 \\
\hline$\omega_{\mathrm{O} 3}$ & 0.19 \\
\hline$\omega_{\mathrm{O} 4}$ & 0.21 \\
\hline$\omega_{\mathrm{O} 5}$ & 0.15 \\
\hline$\omega_{\mathrm{O} 6}$ & 0.14 \\
\hline
\end{tabular}

Figure 5 Weighted $\mathrm{O} / \mathrm{S}$ matrix for the Chinese international construction company

Step Three should have been the assignment of specific coefficients to any two S,W,O,T factors so as to indicate their degrees of relationship. But given the very long list of factors, it was not realistic for busy decision makers to do that. Alternatively, the authors asked them to discuss the potential relationships between the $\mathrm{S}, \mathrm{W}, \mathrm{O}, \mathrm{T}$ factors and coefficients were assigned based on the discussion (e.g. how often/strong they mentioned a congruence). Figure 6 shows the weighted interaction $\mathrm{O} / \mathrm{S}$ matrix for the company as derived. The assignment of coefficients was based on the author's judgment and the discussion given by the attendees.

\begin{tabular}{|c|c|c|c|c|c|c|c|c|c|c|c|c|}
\hline & & & \multicolumn{10}{|c|}{$\begin{array}{l}\text { Internal Strengths } \\
\text { S1: Low cost/good value for money } \\
\text { S2: Abundant cheap manpower } \\
\text { S3: Strong design and construction capacity } \\
\text { S4: Profits from multiple portfolios } \\
\text { S5: Hard working } \\
\text { S6: Reputation } \\
\text { S7: Plenty and cheap construction materials available } \\
\text { S8: Experience in Asia and Africa markets } \\
\text { S9: Strong support from the government } \\
\text { S10: Particularly specialized in housing/office buildings }\end{array}$} \\
\hline & & & $\omega_{\mathrm{S} 1}$ & $\omega_{\mathrm{S} 2}$ & $\omega_{\mathrm{S} 3}$ & $\omega_{\mathrm{S} 4}$ & $\omega_{\mathrm{S} 5}$ & $\omega_{\mathrm{S} 6}$ & $\omega_{\mathrm{S} 7}$ & $\omega_{\mathrm{S} 8}$ & $\omega_{\mathrm{S} 9}$ & $\omega_{\mathrm{S} 10}$ \\
\hline & & & 0.15 & 0.09 & 0.10 & 0.09 & 0.06 & 0.12 & 0.08 & 0.13 & 0.09 & 0.09 \\
\hline $\begin{array}{l}\text { External Opportunities: } \\
\text { O1: More open global construction market }\end{array}$ & $\omega_{\mathrm{O} 1}$ & 0.13 & 0.4 & 0.4 & 0.3 & 0.4 & 0.4 & 0.4 & 0.2 & 0.4 & 0.4 & 0 \\
\hline O2: Domestic construction market is still & $\omega_{\mathrm{O} 2}$ & 0.18 & 0 & 0 & 0.4 & 0.6 & 0 & 0.4 & 0 & 0 & 0 & 0.4 \\
\hline
\end{tabular}


O4: Will be listed in the stock market

O5: Increasing collaboration and partnering amongst international competitors

O6: Globalization provides a chance for leap-forward development

\begin{tabular}{|l|l|l|l|l|l|l|l|l|l|l|l|}
\hline$\omega_{\mathrm{O} 3}$ & 0.19 & 0 & 0 & 0 & 0 & 0 & 0.4 & 0 & 0 & 0.4 & 0.4 \\
\hline$\omega_{\mathrm{O} 4}$ & 0.21 & 0 & 0 & 0 & 0.4 & 0 & 0.15 & 0 & 0 & 0 & 0 \\
\hline$\omega_{\mathrm{O} 5}$ & 0.15 & 0 & 0.5 & 0 & 0 & 0 & 0.4 & 0 & 0 & 0 & 0 \\
\hline$\omega_{\mathrm{O} 6}$ & 0.14 & 0.4 & 0.4 & 0.4 & 0 & 0.3 & 0.15 & 0.4 & 0.4 & 0 & 0 \\
\hline
\end{tabular}

Figure 6 Weighted interaction $\mathrm{O} / \mathrm{S}$ matrix -I for the Chinese international construction company

Step Four was to generate HRs from the weighted interaction $\mathrm{O} / \mathrm{S}$ matrix as shown in Figure 6. The matrix was transformed to matrix as shown in Figure 7 by applying the Formula (9). As described previously in Formulas (10) and (12), the task turns to the search of a Maximum Subarray and/or some slightly sub-maximum subarray from the weighted interaction SWOT matrix. In so doing, the matrix as shown in Figure 7 was further transformed into a new matrix as shown in Figure 8. It is easy to derive the maximum subarray which is shown in Figure 9. The HR associated with the maximum subarray is $\mathrm{HR} 1=\{\mathrm{O} 1, \mathrm{O} 6, \mathrm{~S} 1, \mathrm{~S} 2, \mathrm{~S} 3, \mathrm{~S} 5$, S6, S7, S8\}, where sum(MS $(\mathrm{O} / \mathrm{S}))=0.07042$. We noticed two other subarrays as shown in figures 10 and 11 where sum(MP $(\mathrm{O} / \mathrm{S}))=0.04394$ and 0.0375 collectively. By applying the Formula (12), the membership degrees of the two matrix portions are sum( $\mathrm{MP}(\mathrm{O} / \mathrm{S})) /$ $\operatorname{sum}(\mathrm{MS}(\mathrm{O} / \mathrm{S}))=0.04394 / 0.07042=0.624$ and 0.533 . For any other matrix portion, the membership degree is much smaller than these two. Therefore, we all agreed that the two matrix portions as shown in figures 10 and 11 are important although they are not maximum subarray. This demonstrated how the group used the fuzzy logic to derive some slightly smaller matrix portions in this SWOT analysis. As a result, the maximum subarray and some slightly sub-maximum subarray were derived as highlighted in Figure 8 using different dash lines.

\begin{tabular}{|c|c|c|c|c|c|c|c|c|c|c|c|}
\hline & & $\omega_{\mathrm{s} 1}$ & $\omega_{\mathrm{S} 2}$ & $\omega_{\mathrm{S} 3}$ & $\omega_{\mathrm{S} 4}$ & $\omega_{\mathrm{S} 5}$ & $\omega_{\mathrm{S} 6}$ & $\omega_{\mathrm{S} 7}$ & $\omega_{\mathrm{S} 8}$ & $\omega_{\mathrm{S} 9}$ & $\omega_{\mathrm{s} 10}$ \\
\hline & & 0.15 & 0.09 & 0.10 & 0.09 & 0.06 & 0.12 & 0.08 & 0.13 & 0.09 & 0.09 \\
\hline$\omega_{01}$ & 0.13 & 0.0078 & 0.00468 & 0.0039 & 0.00468 & 0.00312 & 0.00624 & 0.00208 & 0.00676 & 0.00468 & 0 \\
\hline$\omega_{\mathrm{O} 2}$ & 0.18 & 0 & 0 & 0.00720 & 0.00972 & 0 & 0.00864 & 0 & 0 & 0 & 0.00648 \\
\hline
\end{tabular}




\begin{tabular}{|l|l|c|c|c|c|c|c|c|c|c|c|}
\hline$\omega_{\mathrm{O} 3}$ & 0.19 & 0 & 0 & 0 & 0 & 0 & 0.00912 & 0 & 0 & 0.00684 & 0.00684 \\
\hline$\omega_{\mathrm{O} 4}$ & 0.21 & 0 & 0 & 0 & 0.00756 & 0 & 0.00378 & 0 & 0 & 0 & 0 \\
\hline$\omega_{\mathrm{O} 5}$ & 0.15 & 0 & 0.00675 & 0 & 0 & 0 & 0.00720 & 0 & 0 & 0 & 0 \\
\hline$\omega_{\mathrm{O} 6}$ & 0.14 & 0.00840 & 0.00504 & 0.00560 & 0 & 0.00252 & 0.00252 & 0.00448 & 0.00728 & 0 & 0 \\
\hline
\end{tabular}

Figure 7 Weighted interaction $\mathrm{O} / \mathrm{S}$ matrix -II for the Chinese international construction company

\begin{tabular}{|c|c|c|c|c|c|c|c|c|c|c|c|}
\hline & $\omega_{\mathrm{S} 1}$ & $\omega_{\mathrm{S} 2}$ & $\omega_{\mathrm{S} 3}$ & $\omega_{\mathrm{S} 5}$ & $\omega_{\mathrm{S} 6}$ & $\omega_{\mathrm{S} 7}$ & $\omega_{\mathrm{S} 8}$ & $\omega_{\mathrm{S} 4}$ & $\omega_{\mathrm{S} 9}$ & $\omega_{\mathrm{S} 10}$ \\
\hline & & 0.15 & 0.09 & 0.10 & 0.06 & 0.12 & 0.08 & 0.13 & 0.09 & 0.09 & 0.09 \\
\hline$\omega_{\mathrm{O} 1}$ & 0.13 & 0.0078 & 0.00468 & 0.0039 & 0.00312 & to. & 0.00208 & 0.00676 & 0.00468 & 0.0046 & 0 \\
\hline$\omega_{06}$ & 0.14 & $\begin{array}{r}0.0084 \\
-\cdot\end{array}$ & $\begin{array}{r}0.00504 \\
-\cdot-\cdot .-\end{array}$ & $\begin{array}{r}0.0056 \\
-. \cdot .\end{array}$ & $\begin{array}{r}0.00252 \\
-\cdot-\cdot-\cdot\end{array}$ & $b_{00252}$ & $\begin{array}{l}0.00448 \\
-\cdot \cdot \cdot-\end{array}$ & \begin{tabular}{l}
$0.00728 !$ \\
\hdashline
\end{tabular} & 0 & 0 & 0 \\
\hline$\omega_{02}$ & 0.18 & 0 & 0 & 0.0072 & 0 & p. 00864 & 0 & 0 & 0.00972 & 0 & 0.00648 \\
\hline$\omega_{03}$ & 0.19 & 0 & 0 & 0 & 0 & $1^{0.00912}$ & 0 & 0 & 0 & 0.00684 & 0.00684 \\
\hline$\omega_{04}$ & 0.21 & 0 & 0 & 0 & 0 & $i^{0.00378}$ & 0 & 0 & 0.00756 & 0 & 0 \\
\hline$\omega_{05}$ & 0.15 & 0 & 0.675 & 0 & 0 & $\begin{array}{l}!_{0.0072} \\
\vdots \\
-\cdots\end{array}$ & 0 & 0 & 0 & 0 & 0 \\
\hline
\end{tabular}

Figure 8 A transformed weighted interaction $\mathrm{O} / \mathrm{S}$ matrix for the Chinese international construction company

\begin{tabular}{|c|c|c|c|c|c|c|c|c|}
\cline { 3 - 8 } \multicolumn{2}{c|}{} & $\omega_{\mathrm{S} 1}$ & $\omega_{\mathrm{S} 2}$ & $\omega_{\mathrm{S} 3}$ & $\omega_{\mathrm{S} 5}$ & $\omega_{\mathrm{S} 6}$ & $\omega_{\mathrm{S} 7}$ & $\omega_{\mathrm{S} 8}$ \\
\cline { 2 - 9 } & 0.15 & 0.09 & 0.10 & 0.06 & 0.12 & 0.08 & 0.13 \\
\hline$\omega_{\mathrm{O} 1}$ & 0.13 & 0.0078 & 0.00468 & 0.0039 & 0.00312 & 0.00624 & 0.00208 & 0.00676 \\
\hline$\omega_{\text {O6 }}$ & 0.14 & 0.0084 & 0.00504 & 0.0056 & 0.00252 & 0.00252 & 0.00448 & 0.00728 \\
\hline
\end{tabular}

Figure 9 the maximum subarray derived from the weighted interaction $\mathrm{O} / \mathrm{S}$ matrix for the Chinese international construction company

\begin{tabular}{|c|c|c|c|c|c|c|c|c|c|c|}
\hline & & $\omega_{\mathrm{S} 1}$ & $\omega_{\mathrm{S} 2}$ & $\omega_{\mathrm{S} 3}$ & $\omega_{\mathrm{S} 5}$ & $\omega_{\mathrm{S} 6}$ & $\omega_{\mathrm{S} 7}$ & $\omega_{\mathrm{S} 8}$ & $\omega_{\mathrm{S} 4}$ & $\omega_{\mathrm{S} 9}$ \\
\hline & & 0.15 & 0.09 & 0.10 & 0.06 & 0.12 & 0.08 & 0.13 & 0.09 & 0.09 \\
\hline$\omega_{01}$ & 0.13 & 0.0078 & 0.00468 & 0.0039 & 0.00312 & 0.00624 & 0.00208 & 0.00676 & 0.00468 & 0.00468 \\
\hline
\end{tabular}


Figure 10 the slightly sub-maximum subarray I derived from the weighted interaction $\mathrm{O} / \mathrm{S}$ matrix for the Chinese international construction company

\begin{tabular}{|c|c|c|}
\cline { 3 - 3 } \multicolumn{2}{|c|}{} & $\omega_{\mathrm{S} 6}$ \\
\cline { 3 - 3 } & 0.12 \\
\hline$\omega_{\mathrm{O} 1}$ & 0.13 & 0.00624 \\
\hline$\omega_{\mathrm{O} 6}$ & 0.14 & 0.00252 \\
\hline$\omega_{\mathrm{O} 2}$ & 0.18 & 0.00864 \\
\hline$\omega_{\mathrm{O} 3}$ & 0.19 & 0.00912 \\
\hline$\omega_{04}$ & 0.21 & 0.00378 \\
\hline$\omega_{\mathrm{O} 5}$ & 0.15 & 0.0072 \\
\hline
\end{tabular}

Figure 11 the slightly sub-maximum subarray II derived from the weighted interaction $\mathrm{O} / \mathrm{S}$ matrix for the Chinese international construction company

Three HRs associated with the maximum subarray and some slightly sub-maximum subarray were derived: $\mathrm{HR} 1=\{\mathrm{O} 1, \mathrm{O} 6, \mathrm{~S} 1, \mathrm{~S} 2, \mathrm{~S} 3, \mathrm{~S} 5, \mathrm{~S} 6, \mathrm{~S} 7, \mathrm{~S} 8\} ; \mathrm{HR} 2=\{\mathrm{O} 1, \mathrm{O} 2, \mathrm{O} 3, \mathrm{O} 4, \mathrm{O} 5, \mathrm{O} 6$, $\mathrm{S} 6\}$ and $\mathrm{HR} 3=\{\mathrm{O} 1, \mathrm{~S} 1, \mathrm{~S} 2, \mathrm{~S} 3, \mathrm{~S} 4, \mathrm{~S} 5, \mathrm{~S} 6, \mathrm{~S} 7, \mathrm{~S} 8, \mathrm{~S} 9\} . \mathrm{HR} 1$ informs the key decision makers to generate strategic options that can make use of globalization (O6) and the more open international construction market $(\mathrm{O} 1)$ by taking advantage of its existing strengths such as low cost (S1), cheap labour (S2), reputation (S6), materials (S7), etc. HR2 suggested that new strategies should make use of all the opportunities (O1 through to O6) by exploiting its established reputation (S6) in the construction industry. HR3 suggests that, faced with the slowing down of the international market, the company should place more emphasis on its domestic portfolio by using its strengths, e.g. profits from multiple portfolios (S4), support from the government (S9), etc.

Compared to the traditional SWOT analysis which often leads to a plain list of factors only, the case study shows that the new approach did go further and helped to identify some Heuristic Rules which highlight the most influential factors for a strategic planning situation. Today's SWOT analyses tend to generate more and more factors. Without the help of an 
improved approach such as this, it is rather difficult to identify the most influential factors. The Heuristic Rules are more helpful than simple lists of all factors. They allow strategic planners to focus and to devise strategies which make use of these strengths, weaknesses, opportunities, and weaknesses picked out as more important ones.

\section{Discussion: Simplicity of SWOT versus sophisticated maths}

As reviewed above, the longevity of the SWOT analysis lies in many features including its simplicity. Simple is beautiful! It is particularly important for a strategic management tool such as SWOT analysis to maintain its simplicity so senior managements are willing to use it. However, has the new approach adopted in this research deviated from the principle of simplicity by involving mathematics? Reviewers of the proposed work did warn that the new SWOT analysis would appear as inaccessible to users who are not familiar with mathematical language.

Utilization of quantitative approaches, however, has shown great potential for improving the usefulness of a SWOT analysis. The traditional SWOT evaluations are based on highly subjective techniques. Empirical study reveals that a failure to prioritize various factors is one of the main reasons accounting for poor SWOT utilization. In fact, many studies have introduced quantitative methods to prioritize SWOT factors (Hill and Westbrook, 1997; Kurttila et al., 2004). Dyson (2004) also suggests that quantitative methods inherent in Operational Research (OR) are well suited for the handling of strategic issues as they facilitate understanding and learning, and the evaluation of strategies prior to action.

The authors of this paper follow the trend whereby quantitative methods are introduced to improve the traditional SWOT analysis. A highlight of the authors' approach is the determination of various Heuristic Rules, which indicate the most influential SWOT factors, and thus inspires the generation of more promising strategic options. The classic "Maximum Subarray" approach well known in computing science is used here in the search for Heuristic Rules. Nonetheless, like other matrix manipulations, the new approach is hardly user friendly and the simplicity of the SWOT analysis is compromised in this way. 
A closer look, however, indicates it is possible to achieve the improvement without significantly compromising simplicity by encapsulating all the quantitative matrix processes in a computer program. One of the principles of modern software programming is to make complex processes transparent to users. If the complicated processes can be transparently encapsulated, strategists, as usual, need only to focus on the evaluation of SWOT factors and their relationships. In comparison with work on an A3 flipchart, it is simpler to add, delete, and modify SWOT factors in a computer program. The result is also available for future use if it is stored in a computer. The calculations underlying the new SWOT analysis are easily coped with by the normal personal computer (PC). Nonetheless, in spite of many existing algorithms for searching for the maximum subarray, there is no such a computer program readily available for achieving strategic heuristic rules in this study. Future research, therefore, was recommended to develop a practical software package for this SWOT analysis based on the proposed SWOT approach. The processes of conducting the SWOT analysis with computer assistance, as proposed, should be overseen by a facilitator, a practice increasingly observed in modern strategic management exercises.

\section{Conclusions}

The research described in this paper has shown that by introducing mathematical quantifying techniques involving Maximum Subarrary and fuzzy set theory, the traditional SWOT analysis can be made more helpful. The method distils SWOT analysis data and consolidates it into Heuristic Rules which bring into focus those most influential contextual factors for the information of a strategic planner, thus better assisting the formulation of proper strategies. Although the proposed improved SWOT approach has been generated and validated in the context of the construction industry, it does not exclude its use in other industries. Further research is recommended to look at its applicability to the other industry sectors.

Nevertheless, since matrix manipulations and other calculations are involved, the new SWOT analysis mathematical processes need to be encapsulated in a 'black box' as far as top executives are concerned. The black box is envisaged as a computer package which takes the 
SWOT analysis as input. Nevertheless it is not the contention of this paper that rational analysis can fully bridge the gap between a SWOT analysis and the formulation of strategies. Strategic planning is both a science and an art requiring judgment.

\section{Acknowledgement}

The authors would like to thank the Innovative Construction Research Centre (ICRC) at the University of Reading for the valuable support for developing this idea. Special thanks are given to Emeritus Professor Mike Anson at the Hong Kong Polytechnic University for his generous help and truly constructive comments on this paper. Mr. PENG Yi and the three anonymous reviewers are also highly appreciated as they make this paper more robust.

\section{References}

Amram, M., \& Kulatilaka, N. (1998), Real options: Managing strategic investment in an uncertain world. Harvard Business School Press: Boston.

Bae, S.E. and Takaoka, T. (2005), Improved Algorithms for the K-Maximum Subarray Problem, The Computer Journal, 49(3), 358-374.

Beer, M., Voelpel, S.C., Leibold, M. and Tekie, E.B. (2005), Strategic management as organizational learning: developing fit and alignment through a disciplined process, Long Range Planning, 38, 445-465.

Bentley, J. (1984), Programming pearls: algorithm design techniques, Communication of $A C M, 27(9), 865-873$.

Betts, M., and Ofori, G. (1992), Strategic planning for competitive advantage, Construction Management and Economics, 10(6), 511-532.

Betts, M., and Ofori, G. (1994), Strategic planning for competitive advantage in construction: the institutions, Construction Management and Economics, 12 (6), 203-217.

Betts, M., Cher, L., Mathur, K. and Ofori, G. (1991), Strategies for the construction sector in the information technology era, Construction Management and Economics, 9(6), 509-528.

Boden, M. A.(1995), Creativity and unpredictability, Stanford Education and Humanities Review, 4(2).

Bowman, E. H., \& Moskowitz, G. T. (2001), Real options analysis and strategic decision making, Organization Science, 12, 772-777.

Cooke, S. and Slack, N. (1991), Making Management Decisions, 2nd Ed., Prentice Hall. 
Dalkey N. and Helmer O (1963), An experimental application of the Delphi Method to the use of experts, Management Science, 9(3), 458-467.

Dyson, R.G. (2004), Strategic development and SWOT analysis at the University of Warwick, European Journal of Operational Research,152, 631-640.

Dyson, R.G.. (1990), Strategic Planning: Models and Analytical Techniques, John Wiley \& Sons: New York.

EL-Nasr M.S., Yen J., and Loerger T.R. (2000), Flame-fuzzy logic adaptive model of emotions, Autonomous Agents and Multi-Agent Systems, 3, 219-257.

Elbanna, S. and Child, J. (2007), Influences on strategic decision effectiveness: development and test of an integral model, Strategic Management Journal, 28, 431-453.

ENR: Engineering News-Record (2008), The top 225 international contractors, Engineering News-Record, 261(5), 32-37.

Flanagan, R., Lu, W.S., Shen, L.Y., Jewell, C.A. (2007), Competitiveness in construction: a critical review of research, Construction Management and Economics, 25, 989-1000.

Glaister, K.W. and Falshaw, J.R. (1999), Strategic planning: still going strong?, Long Range Planning, 32(1), 107- 116.

Haan J.D., Voordijk H. and Joostern J. (2002), Market strategies and core capabilities in the building industry, Construction Management and Economics, 20(2), 109-118.

Hill, T. and Westbrook, R. (1997), SWOT Analysis: It's Time for a Product Recall, Long Range Planning, 30 (1), 46-52.

Kale, S. (2002), Competitive advantage in the construction industry: firm-specific resources and strategy, A thesis submitted to the Degree of Doctor of Philosophy in Civil Engineering of Illinois Institute of Technology, Anbor, Mich. : UMI.

Kale, S. and Arditi, D. (2002), Competitive positioning in United States construction industry, Journal of Construction Engineering and Management ASCE, 128(3), 238-247.

Khatri, N. and Ng, H.A. (2000), The role of intuition in strategic decision making, Human Relations, 53(1), 57-86.

Kolter, P. (1988), Marketing Management: Analysis, Planning, Implementation, and Control, 6th Ed., Prentice-Hall International Edition.

Kurttila, M., Pesonen M., Kangas, J., Kajanus, M. (2000), Utilizing the analytical hierarchy process (AHP) in SWOT analysis - a hybrid method and its application to a forest-certification case, Forest Policy and Economics, 1 (1), 41-52.

Learned, E.P., Christensen, C.R., Andrews, K.E., Guth, W.D. (1965), Business Policy: Text and Cases, Irwin, Homewood:IL.

Lu, W.S., Li, H., Shen, L.Y., and Huang, T. (2009), A SWOT analysis of Chinese construction 
companies in the global market, ASCE Journal of Management in Engineering, Forthcoming.

Lu, W.S., Shen, L.Y., and Yam, M.C.H. (2008), Critical Success Factors for Competitiveness of Contractors: China Study, ASCE Journal of Construction Engineering and Management, 134(12), 972-982.

Miller, C.C. and Cardinal, L.B. (1994), Strategic planning and firm performance: a synthesis of more than two decades of research, Academy of Management Journal, 37(6), 1649-1665.

Panagiotou, G. (2003), Bringing SWOT into focus, Business Strategy Review, 14(2),8-10.

Piercy, N. (1991), Marketing-led Strategic Change, Oxford: Butterworth-Heinemann.

Porter, M.E. (1980), Competitive Strategy: Techniques for Analysing Industries and Competitors, Free Press, New York/Collier Macmillan, London.

Porter, M.E. (1985), Competitive Advantage: Creating and Sustaining Superior Performance, Free Press, New York/Collier Macmillan, London.

Ribeaux, P. and Poppleton, S.(1978), Psychology and Work, Macmillan.

Saaty, T.L. (1980), The Analytic Hierarchy Process. Planning, Priority Setting, Resource Allocation. McGraw-Hill.

Shen L Y, Zhao Z Y and Drew D (2006) 'Strengths, Weaknesses, Opportunities and Threats (SWOT) for Foreign-Invested Construction Enterprises: a China Study', ASCE Journal of Construction Engineering and Management, 132(9), 966-976.

Sun Tzu, The Art of War. BC600.

Takaoka, T. (2002), Efficient algorithms for the Maximum Subarray problem by distance matrix multiplication, Electronic Notes in Theoretical Computer Science, 61(January): 191-200.

Venegas P.C. and Alarcon L.F. (1997), Selecting long-term strategies for construction firms, Journal of Construction Engineering and Management ASCE, 123(4), 388-398.

Warszawski, A. (1996), Strategic planning in construction companies, Journal of Construction Engineering and Management ASCE, 122(2), 133-140.

Weihrich, H. (1982), the TOWS matrix: a tool for situational analysis, Long Range Planning, $15(2), 54-66$.

Wheelen, T.L., and Hunger, J.D. (1995), Strategic Management and Business Policy, (5th ed.) Addison Wesley, Reading, MA.

Zadeh, L. (1965), Fuzzy sets, Information and Control, 8, 338-353. 